Nilton S. Formiga, Gislane Melo, Verificação Empírica da Escala das Atividades de Hábitos de Lazer... Sérvulo Fernando C. Lima

\title{
VERIFICAÇÃO EMPÍRICA DA ESCALA DAS ATIVIDADES DE HÁBITOS DE LAZER EM JOVENS ESPORTISTAS E NÃO ESPORTISTAS DAS CIDADES DE TERESINA - PI E JOÃO PESSOA - PB
}

\author{
Recebido em: 07/07/2012 \\ Aceito em: 21/01/2013 \\ Nilton Soares Formiga ${ }^{1}$ \\ Faculdade Mauricio de Nassau - FMN \\ João Pessoa - PB - Brasil \\ Gislane Melo ${ }^{2}$ \\ Universidade Católica de Brasilia - UCB \\ Brasília - DF - Brasil \\ Sérvulo Fernando Costa Lima ${ }^{3}$ \\ Instituto Federal do Piauí - IFPI \\ Teresina - PI - Brasil
}

RESUMO: O presente estudo tem como objetivo verificar a estrutural fatorial da escala de atividades dos hábitos de lazer em jovens atletas e não atletas. Os hábitos de lazer favorecem um equilíbrio para conduzir às pessoas a prática do repouso, relações sociais e a diversão. Assim, neste contexto, o lazer refere-se as maneiras de passar o tempo livre, quando já se cumpriu os afazeres e compromissos cotidianos, atendendo as necessidades básicas de enriquecimento intelectual e cultural e descanso. A amostra foi composta por 261 homens e mulheres, de 14 a 18 anos de idade, do nível médio de uma escola particular da cidade de João Pessoa-PB e publica da cidade de Teresina-PI, destes, 113 eram atletas e 148 não atletas. Eles responderam a escala das atividades de hábitos de lazer na sala de aula. Efetuou-se a análise de modelagem de equação estrutural e observaram-se indicadores estatísticos que confirmaram a estrutura fatorial na amostra de atletas e de não atletas, a qual, semelhante a encontrada em estudos anteriores, corroborando o seu uso para o contexto brasileiro.

PALAVRAS CHAVE: Escalas. Atividades de Lazer. Adolescente. Atletas.

\section{EMPIRICAL VERIFICATION OF THE LEISURE HABITS ACTIVITIES SCALE IN SPORTS AND NON-SPORTS YOUNG CITY OF CIDADE DE TERESINA - PI AND JOÃO PESSOA-PB}

ABSTRACT: This study aims to verify the structural factor of leisure habits scale in young athletes and nonathletes. Leisure habits promote a balance to drive people to the practice of rest, social relationships and fun. Therefore, in this context, leisure refers to

\footnotetext{
${ }^{1}$ Doutor em Psicologia Social pela Universidade Federal da Paraíba. Atualmente é professor do curso de Psicologia na Faculdade Mauricio de Nassau - JP.
} 
Nilton S. Formiga, Gislane Melo, Verificação Empírica da Escala das Atividades de Hábitos de Lazer... Sérvulo Fernando C. Lima

the ways of spending free time, when they have complied with the daily chores and appointments, meeting the basic needs of intellectual and cultural enrichment and rest. The sample was composed by 261 men and women with 14-18 years of age, from a private high school in the city of João Pessoa and a public high school from the city of Teresina-PI, of whom 113 were athletes and 148 were nonathletes. They answered the Leisure Habits Activities Scale in the classroom. We conducted the analysis of structural equation modeling and observed statistical indicators confirmed the factor structure in the sample of athletes and nonathletes, which resembles that found in previous studies, supporting its use in the Brazilian context.

KEYWORDS: Scales. Leisure Activities. Adolescent. Athletes.

\section{INTRODUÇÃO}

As formas e o tempo da diversão além de assumir uma função de sociabilidade contribuem para uma organização psicológica na vida dos jovens, seus pares de iguais e instituições formadoras da conduta socialmente desejável (por exemplo, família, escola, etc.); com as atuais condições sociais, culturais e urbanas ainda têm se discutido nas diversas áreas científicas sobre o tema (Psicologia, Educação Física, etc.), bem como, áreas afins (Educação, Serviço Social, etc.), a organização e avaliação dessas categorias da diversão (leia-se lazer) e a influência delas na conduta juvenil. Desta maneira, questiona-se: qual a contribuição dos tipos e formas de lazer para a construção e organização de fatores psicológicos, sociais e interpessoais na vida dos jovens?

Essa preocupação deve-se ao fato de que, a ocupação do jovem com algo social ou afetivo na dinâmica interpessoal do lazer, tem como pressuposto a necessidade de que ele tenha uma satisfação com o que está fazendo, bem como, venha a gerar uma manutenção do lazer que seja capaz de produzir fatores de proteção individual e social quando em diversão. De acordo com Pais (1998), o cotidiano das pessoas pode proporcionar atividades capazes de construir hábitos, seja para o indivíduo sozinho ou um grupo, formando costumes de prazer ou aborrecimento, de informação e envolvimento social. Com isso, Formiga, Ayroza e Dias (2005) e Formiga, Bonato e 
Nilton S. Formiga, Gislane Melo, Verificação Empírica da Escala das Atividades de Hábitos de Lazer... Sérvulo Fernando C. Lima

Sarriera (2011) enfatizam que no lazer deve existir um investimento e dedicação, isto é, que cada pessoa, mesmo com diferentes maneiras de passar o seu tempo livre, principalmente, quando já se cumpriu os afazeres e compromissos cotidianos, deverá ter a forma do lazer como uma meta que atenda as suas necessidades básicas: repouso, diversão ou de enriquecimento intelectual e cultural; mas, também, contribua para a saúde do seu entorno social e institucional (família e escola).

Desta maneira, segundo Formiga, Ayroza e Dias (2005), um hábito de lazer corresponde, geralmente, ao que o sujeito aprendeu e apreendeu durante o seu desenvolvimento com os pares de iguais ou pares sócio-normativos (pais, professores, etc.), passando a repeti-lo e levando ao costume (por exemplo: o gosto pela leitura, às práticas religiosas, participação em festas, etc.); esses hábitos devem contribuir para o jovem a busca de equilíbrio entre o fazer e o pensar da prática do repouso e relações sociais, mas, antes de tudo, deve-se apresentar como atitudes favoráveis frente mais ao SER do que ao TER, de tal forma que em sua investida na diversão experimentada ele venha a se desenvolver psicologicamente confrontando seus medos, vontades, valores, emoção, etc. (FORMIGA; AYROZA; DIAS, 2005; FORMIGA; DIAS, 2002).

A literatura sobre o tema do lazer apresentam reflexões muito importantes sobre o que, como e onde fazer com o espaço e as pessoas da diversão (REQUIXÁ, 1974; DUMAZEDIER, 1999; PERREIRA，1987; WERNECK, 2000; ANDRADE，2001; MARCELINO, 1998; 2000; SAMPAIO; SILVA, 2011); porém, como avaliar e mensurar esses elementos formadores do lazer? Foi partindo dessa perspectiva que Formiga, Ayroza e Dias (2005), a fim de avaliar, empiricamente, os hábitos de lazer em jovens, desenvolveram uma escala, esta, era composta por vinte quatro itens que avaliavam as atividades de lazer assumidas pelos jovens quando estes haviam cumprido 
Nilton S. Formiga, Gislane Melo, Verificação Empírica da Escala das Atividades de Hábitos de Lazer... Sérvulo Fernando C. Lima

todas as atividades consideradas importantes e obrigatórias exigidas pela família, escola, etc. (por exemplo, estudar, visitar familiares, etc.); os itens referidos a escala de lazer (ver anexo) deveriam ser respondido numa escala de seis pontos, tipo Likert, com os extremos entre $0=$ Nunca a $5=$ Sempre. Os autores observaram, a partir de uma análise fatorial exploratória, dos componentes principais, a existência de três fatores, os quais possuem conceitos específicos, a saber:

- O primeiro deles descrito como Hábito de Lazer Hedonista (Este fator, diz respeito aos hábitos de consumo que enfatizam o prazer individual e imediato como único bem possível do indivíduo; por exemplo, Ir a shows, teatro, etc; Ir ao cinema; Navegar na internet, etc.);

- O segundo fator, Hábito Lúdico (Refere-se a utilização de jogos, brinquedos, passeio e divertimentos em geral, apresentando um caráter instrumental do lazer e de envolvimento emocional positivo; por exemplo, Praticar esportes; Assistir programas de televisão; Jogar vídeo games, jogos de ação ou aventura etc.);

- Por fim, o terceiro, Hábito Instrutivo (Enfatizando a experiência de aperfeiçoamento e crescimento desenvolvido pelos sujeitos tornando-os capaz de certas escolhas de lazer diferenciadas e exclusivas para eles, como também, pode assumir uma atividade quanto a transmissão, habilitação e ensino de conhecimentos; por exemplo, Ler livros; Ler revistas; Visitar familiares etc.).

Sendo assim, Formiga, Bonato e Sarriera (2011) e Formiga (2012), com base no estudo de Formiga, Ayroza e Dias (2005) realizaram uma análise estatística (análise de modelagem estrutural) de forma mais sofisticada e robusta visando a comprovação empírica tanto da escala quanto da perspectiva conceitual, bem como, a possibilidade da redução dos itens por fatores, proposta pelos autores supracitados. Em ambos os estudos 
Nilton S. Formiga, Gislane Melo, Verificação Empírica da Escala das Atividades de Hábitos de Lazer... Sérvulo Fernando C. Lima

(FORMIGA; BONATO; SARRIERA, 2011; FORMIGA, 2012), observaram-se uma consistência e acurácia estatística da escala em diferentes amostras; assim, a escala organizou-se em quinze itens, ao invés de vinte quatro, com todos eles distribuídos em três fatores e os respectivos itens, semelhante ao encontrando por Formiga, Ayroza e Dias (2005) em seu primeiro estudo: Formiga (2012) observou uma estrutura que, seja em amostra de jovens de escolas publicas ou particulares, os hábitos de lazer se organizam em três grupos (hábitos hedonistas, lúdicos e instrutivos), na mesma direção, em um ano anterior, Formiga, Bonato e Sarriera (2011), em amostras de diferentes estados brasileiros, encontraram resultados que corresponderam à mesma estrutura proposta. Com isso, além de corroborar a estrutura da escala, o instrumento sugere, em sua nova modalidade, uma segurança semântica, metodológica e de economia de tempo de aplicação e material.

Apesar de tais estudos apresentarem indicadores estatísticas confiáveis que comprovam a estrutura e consistência interna da escala avaliada, seguiu-se a sugestão de Formiga, Bonato e Sarriera (2011) quanto a avaliação da escala tanto em relação ao tempo e o contexto de aplicação, quanto com a sua administração em diferentes amostras (por exemplo, em jovens atletas e não atletas) a fim de garantir a organização do construto e estrutural da escala sobre as atividades dos hábitos de lazer. Desta maneira, o presente estudo tem como objetivo, avaliar a organização estrutural da escala das atividades dos hábitos de lazer em amostra de jovens que praticam esportes de competição (Basquetebol, Voleibol, Handebol e Futsal) e os que não praticam. Esperase que a escala apresente uma organização em sua estrutura item-fator semelhante a que vem sendo encontrada pelos autores quando no uso dessa escala em jovens, corroborando o construto das atividades dos hábitos de lazer. 
Nilton S. Formiga, Gislane Melo, Verificação Empírica da Escala das Atividades de Hábitos de Lazer... Sérvulo Fernando C. Lima

\section{MÉTODO}

\section{Amostra}

O presente estudo trata-se de uma pesquisa de campo, com foco quantitativo, para a qual, 261 homens e mulheres, de 14 a 18 anos de idade, de escola pública e particular do ensino fundamental e médio distribuídas nas cidades de Teresina - PI e João Pessoa-PB compuseram a amostra. Desses sujeitos, 113 eram esportistas das modalidades de Basquetebol, Voleibol, Handebol e Futsal, de uma instituição de ensino federal no Piauí e 148 eram não esportistas da cidade de João Pessoa-PB. Esta amostra foi intencional, considerou-se a pessoa, quando consultada, dispusera-se a colaborar respondendo o questionário a ela apresentado.

\section{Instrumento}

Os participantes responderam um instrumento que constava:

- Escala das Atividades de Hábitos de Lazer - EAHL (Anexo). Elaborado originalmente em português por Formiga, Ayroza e Dias (2005), o instrumento é composto por 24 itens que avaliam as atividades de lazer assumido por cada sujeito a respeito da sua ocupação quando não se está fazendo nada (por exemplo, Ler livros, Ler revistas, For a igreja, Navegar na internet, Comprar roupas, etc.). Para respondê-lo a pessoa deve ler cada item e indicar com que freqüência ocupa seu tempo quando está sem fazer nada, depois de todas suas obrigações cumpridas, utilizando para tanto uma escala de seis pontos, tipo Likert, com os seguintes extremos: $\mathbf{0}=$ Nunca e $\mathbf{5}=$ Sempre (ver Anexo).

A escala revelou, a partir de uma análise exploratória, a existência de três fatores, explicando em seu conjunto $27,9 \%$ da variância total, sendo os seguintes: $\underline{\text { Instrutivo }}$ Lúdico e Hedonismo. Os indicadores de consistência interna estiveram, 
Nilton S. Formiga, Gislane Melo, Verificação Empírica da Escala das Atividades de Hábitos de Lazer... Sérvulo Fernando C. Lima

respectivamente, entre 0,63 a 0,80. Em um estudo em 2011, Formiga, Bonato e Sarriera (2011), a partir da analise de modelagem estrutural propôs a redução da escala para quinze itens, observaram a consistência estrutural desta escala em diferentes Estados brasileiros revelando indicadores psicométricos aceitáveis pela literatura sobre o tema.

Uma folha separada foi anexada ao instrumento onde eram solicitadas informações de caráter sócio-demográfico (por exemplo, idade, sexo, estado civil e classe social).

\section{Procedimentos}

Todos os procedimentos adotados nesta pesquisa seguiram as orientações previstas na Resolução 196/96 do CNS e na Resolução 016/2000 do Conselho Federal de Psicologia (CNS, 1996; ANPEPP, 2000).

\section{$\underline{\text { Administração }}$}

Procurou-se definir um mesmo procedimento padrão científico e ético que consistia em aplicar a escala de atividades de hábitos de lazer coletivamente em sala de aula ou individualmente quando os sujeitos eram esportistas. Colaboradores com experiência na administração de questionários ficaram responsáveis pela coleta dos dados, os quais se apresentavam em sala de aula ou individualmente como interessado em conhecer as opiniões e os comportamentos das pessoas sobre seus hábitos de lazer no dia a dia.

Era solicitado aos sujeitos a colaboração voluntária deles no sentido de responderem um questionário breve. Dizia-lhes que não havia resposta certa ou errada, e que respondesse individualmente, a todos era assegurado o anonimato das suas respostas, que seriam tratadas em seu conjunto. Apesar de o questionário ser autoaplicável, contando com as instruções necessárias para que possam ser respondidos, os 
Nilton S. Formiga, Gislane Melo, Verificação Empírica da Escala das Atividades de Hábitos de Lazer... Sérvulo Fernando C. Lima

colaboradores na aplicação estiveram presentes durante toda a aplicação para retirar eventuais dúvidas ou realizar esclarecimentos que se fizessem indispensáveis. Um tempo médio de 25 minutos foram suficientes para concluir essa atividade.

Quanto à análise dos dados, tomando com base o estudo de Formiga, Ayroza e Dias (2005) e Formiga, Bonato e Sarriera (2011), a partir da análise exploratória e confirmatória realizada por esses autores, efetuou-se uma análise de modelagem estrutural, pretendendo testar a adequação do modelo multidimensional já encontrada em outras amostras, mas, objetivando avaliar semelhante estrutura com amostra de sujeitos esportistas e não esportistas.

Considerou-se como entrada a matriz de covariâncias, tendo sido adotado o estimador ML (Maximum Likelihood). Este tipo de análise estatística é mais criterioso e rigoroso do que a desenvolvida em um primeiro estudo por Formiga, Ayroza e Dias (2005); isto permite testar diretamente uma estrutura teórica a que se propõem neste estudo. Esta análise apresenta alguns índices que permitem avaliar a qualidade de ajuste do modelo proposto (BILICH; SILVA; RAMOS, 2006; BYRNE, 1989; HAIR; et al,2005; KELLOWAY, 1998; TABACHNICK; FIDELL, 1996; VAN DE VIJVER; LEUNG, 1997), por exemplo:

- O $\chi^{2}$ (qui-quadrado) testa a probabilidade de o modelo teórico se ajustar aos dados; quanto maior este valor pior o ajustamento. Este tem sido pouco empregado na literatura, sendo mais comum considerar sua razão em relação aos graus de liberdade $\left(\chi^{2} /\right.$ g.l.). Neste caso, valores até 3 indicam um ajustamento adequado.

- O Goodness-of-Fit Index (GFI) e o Adjusted Goodness-of-Fit Index (AGFI) são análogos ao $\mathrm{R}^{2}$ em regressão múltipla. Portanto, indicam a proporção de variância-covariância nos dados explicada pelo modelo. Estes variam de 0 a 1, com 
Nilton S. Formiga, Gislane Melo, Verificação Empírica da Escala das Atividades de Hábitos de Lazer... Sérvulo Fernando C. Lima

valores na casa dos 0,80 e 0,90 , ou superior, indicando um ajustamento satisfatório (HAIR; et al.,2005; BILICH; SILVA; RAMOS, 2006).

- A Root-Mean-Square Error of Approximation (RMSEA), com seu intervalo de confiança de 90\% (IC90\%), é considerado um indicador de "maldade" de ajuste, isto é, valores altos indicam um modelo não ajustado. Assume-se como ideal que o RMSEA se situe entre 0,05 e 0,08, aceitando-se valores de até 0,10 (GARSON, 2003; KELLOWAY, 1998).

- O Comparative Fit Index (CFI) - compara de forma geral o modelo estimado e o modelo nulo, considerando valores mais próximos de um como indicadores de ajustamento satisfatório (HAIR; ANDERSON; TATHAM; BLACK, 2005; BILICH; SILVA; RAMOS, 2006).

- O Expected Cross-Validation Index (ECVI) e o Consistent Akaike Information Criterion (CAIC) são indicadores geralmente empregados para avaliar a adequação de um modelo determinado em relação a outro. Valores baixos do ECVI e CAIC expressam o modelo com melhor ajuste (HAIR; ANDERSON; TATHAM; BLACK, 2005; BILICH; SILVA; RAMOS, 2006).

\section{RESULTADOS}

No presente estudo, buscou-se avaliar a estrutura da Escala das atividades dos hábitos de lazer (EAHL) em diferentes amostras de jovens, consideraram-se atletas e não atletas. Efetuou-se, no pacote estatístico AMOS 16.0, uma análise fatorial confirmatória e modelagem de equação estrutural para as referidas amostras, tinha-se como hipótese a existência dos três fatores, de acordo com a estrutura proposta por Formiga, Bonato e Sarriera (2011), a saber: hábitos de lazer hedonistas (HL 01, HL 02, 
Nilton S. Formiga, Gislane Melo, Verificação Empírica da Escala das Atividades de Hábitos de Lazer... Sérvulo Fernando C. Lima

HL 03, HL 04, HL 05, HL 06, HL 07), hábitos de lazer lúdicos (HL 08, HL 09, HL 10, HL 11) e hábitos de lazer instrutivos (HL 12, HL 13, HL 14, HL 15) e corroborada por Formiga (2012).

Optando-se por deixar livre as covariâncias (phi, $\varphi$ ) entre os fatores, os indicadores de qualidade de ajuste do modelo para a amostra geral, a amostra dos jovens atletas e a dos não atletas, se mostraram próximas as recomendações apresentadas na literatura (BYRNE, 1989; TABACHNICK; FIDELL, 1996; VAN DE VIJVER; LEUNG, 1997). Os resultados obtidos nestas análises (TAB. 1) revelam modelo trifatorial, em todas as amostras, como o mais adequado para mensurar as atividades dos hábitos de lazer em jovens, sejam estes, atletas ou não.

\section{TABELA 1}

Indicadores psicométricos da estrutura fatorial da escala das atividades de hábitos de lazer em atletas e não atletas.

\begin{tabular}{|c|c|c|c|c|c|c|c|c|c|}
\hline AMOSTRAS & $\chi^{2} / g 1$ & RMR & GFI & $\begin{array}{l}\text { AGF } \\
\text { I }\end{array}$ & CFI & TLI & $\begin{array}{l}\text { RMSEA } \\
\text { (intervalo) }\end{array}$ & CAIC & $\begin{array}{l}\text { ECVI } \\
\text { (intervalo) }\end{array}$ \\
\hline $\begin{array}{l}\text { Amostra } \\
1^{*}\end{array}$ & 2,11 & 0,06 & 0,97 & 0,93 & $\begin{array}{l}0,9 \\
9\end{array}$ & $\begin{array}{l}0,9 \\
8\end{array}$ & $\begin{array}{l}0,02 \\
(0,00- \\
0,04)\end{array}$ & 448,11 & $\begin{array}{l}0,73 \\
(0,70-0,82)\end{array}$ \\
\hline $\begin{array}{l}\text { Amostra } \\
2^{* *}\end{array}$ & 2,09 & 0,08 & 0,91 & 0,86 & $\begin{array}{l}0,9 \\
7\end{array}$ & $\begin{array}{l}0,9 \\
8\end{array}$ & $\begin{array}{l}0,03 \\
(0,00- \\
0,06)\end{array}$ & 334,94 & $\begin{array}{l}1,53 \\
(1,46-1,76)\end{array}$ \\
\hline $\begin{array}{l}\text { Amostra } \\
3^{* * *}\end{array}$ & 2,03 & 0,07 & 0,97 & 0,95 & $\begin{array}{l}0,9 \\
9\end{array}$ & $\begin{array}{l}0,9 \\
9\end{array}$ & $\begin{array}{l}0,01 \\
(0,00- \\
0,05)\end{array}$ & 354,85 & $\begin{array}{l}1,28 \\
(1,18-1,37)\end{array}$ \\
\hline
\end{tabular}

Notas: *Modelo amostra total; **Modelo amostra jovens atletas; ***Modelo amostra jovens não atletas. $\mathrm{p}>0,05$.

Considerando as saturações (Lambdas, $\lambda$ ), todas estiveram dentro do intervalo esperado $\mid 0$ - 1| e são estatisticamente diferentes de zero $(\mathrm{t}>1,96, \mathrm{p}<0,05)$; denotou-se, em relação a amostra total, bem como, as demais (de jovens atletas e não atletas), que não há problemas de estimativa para corroborar a existência dos três fatores para se avaliar as atividades dos hábitos de lazer em diferentes jovens, especialmente, aqueles 
Nilton S. Formiga, Gislane Melo, Verificação Empírica da Escala das Atividades de Hábitos de Lazer... Sérvulo Fernando C. Lima

relacionados aos esportes coletivos de competição e os que não fazem parte desse espaço de desporto.

De forma geral, as associações entre as dimensões foram positivas, o que significa dizer que a existência de uma dessas formas de lazer, possivelmente, influenciará as outras formas. A fim de facilitar a leitura da associação entre esses fatores dos hábitos de lazer será apresentado, separadamente, as figuras que foram geradas com cada amostra. Assim, na (FIG. 1), é possível observar as associações entre as dimensões dos hábitos de lazer, considerando a amostra total, corroborando o modelo proposto.

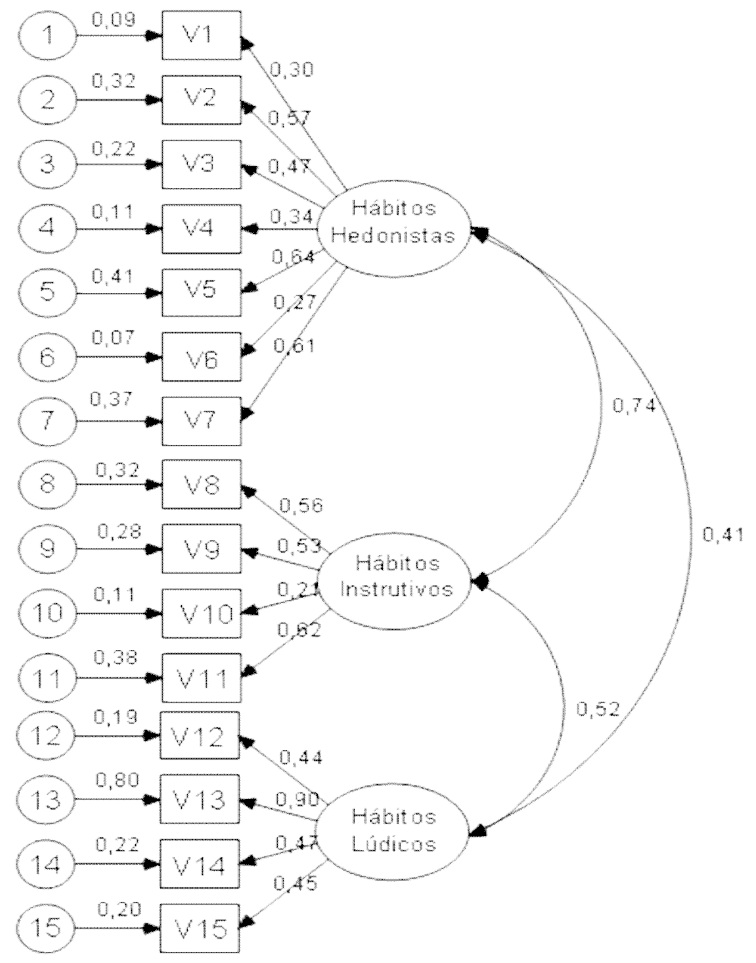

FIGURA 1: Estrutura fatorial da EHL na amostra geral

Na FIG.2, observa-se, também, uma associação positiva entre fatores dos hábitos de lazer, especificamente, para a amostra de jovens atletas. Também, de acordo com o esperado, a estrutura da escala revelou uma associação positiva entre os fatores com a 
Nilton S. Formiga, Gislane Melo, Verificação Empírica da Escala das Atividades de Hábitos de Lazer... Sérvulo Fernando C. Lima

amostra de jovens atletas; esses resultados revelam que esta escala é adaptada para esse grupo de jovens. Apesar de se observar associações menores entre os fatores do que as encontradas na amostra total e nos estudos supracitados (FORMIGA; BONATO; SARRIERA, 2011; FORMIGA, 2012), esses resultados já eram esperados, pois a escala foi desenvolvida para uma amostra de jovens não atletas, fazendo com que os resultados dessa estrutural não sejam descartados e sim devendo ser visto como uma peça na interpretação e adaptação da escala avaliada para esse grupo.

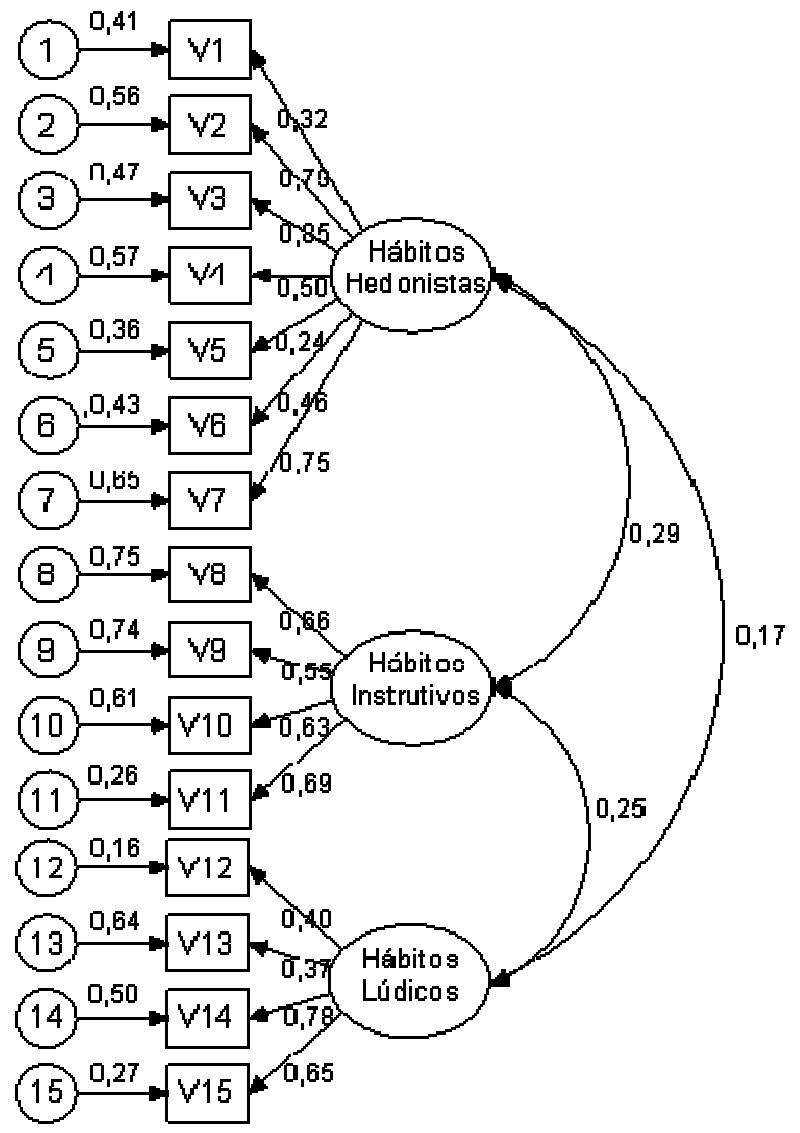

FIGURA 2: Estrutura fatorial da EHL na amostra de jovens atletas.

Na FIG. 3 é apresentada a estrutura da escala de hábitos de lazer para a amostra dos jovens não atletas; esses resultados apresentaram uma associação positiva entre 
Nilton S. Formiga, Gislane Melo, Verificação Empírica da Escala das Atividades de Hábitos de Lazer... Sérvulo Fernando C. Lima

fatores, comprovando a organização item-fator já encontrada por (FORMIGA; BONATO E SARRIERA, 2011; FORMIGA, 2012) revelando que esta escala é adaptada e consistente para esse grupo de jovens, tendo seus indicadores psicométricos, para tal amostra, consistência e próximos às recomendações da literatura estatística (BYRNE, 1989; VAN DE VIJVER; LEUNG, 1997).

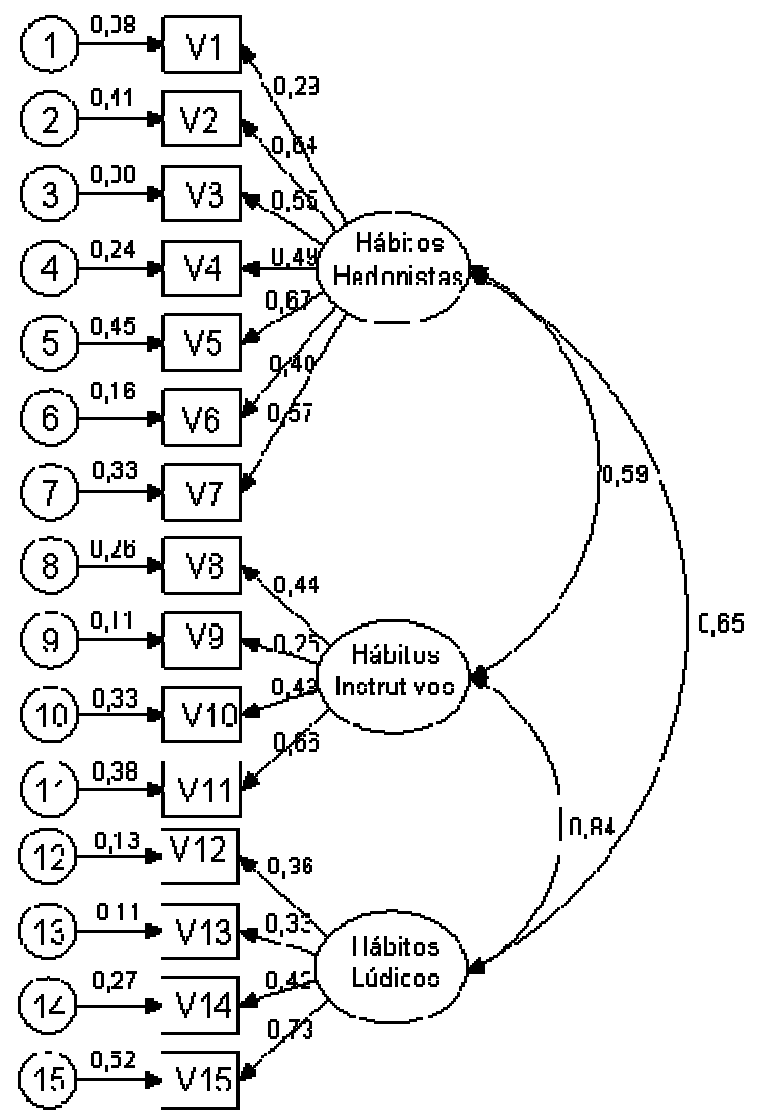

FIGURA 3: Estrutura fatorial da EHL na amostra de jovens não atletas

Comprovada estrutura fatorial que se esperava, realizou-se uma anova one-way entre os fatores das atividades dos hábitos de lazer e o grupo amostral (atletas e não atletas); os resultados foram os seguintes: 
Nilton S. Formiga, Gislane Melo, Verificação Empírica da Escala das Atividades de Hábitos de Lazer... Sérvulo Fernando C. Lima

- em relação ao fator lazer hedonista, os sujeitos atletas apresentaram media superior $\left(\mathrm{M}=2,85, \mathrm{DP}=0,88 ; \mathrm{IC}_{95 \%}-2,70-2,99\right)$ do que a dos não atletas $(\mathrm{M}=2,61$, $\left.\mathrm{DP}=0,67 ; \mathrm{IC}_{95 \%}-2,49-2,74\right)[F(1,261)=5,53, p<0,01]$

- já no que se refere ao lazer lúdico, os sujeitos não atletas tiveram maior media $\left(\mathrm{M}=2,38, \mathrm{DP}=0,80 ; \mathrm{IC}_{95 \%}-2,25-2,52\right)$ do que a dos atletas $(\mathrm{M}=1,95, \mathrm{DP}=0,81$; $\left.\mathrm{IC}_{95 \%}-1,81-2,11\right)[F(1,261)=17,74, p<0,01]$;

- por fim, o lazer instrutivo seguiu direção semelhante a do lazer lúdico, isto é, os sujeitos não atletas tiveram maior media $\left(\mathrm{M}=2,42, \mathrm{DP}=0,82 ; \mathrm{IC}_{95 \%}-2,29-2,56\right)$ do que a dos atletas $\left(\mathrm{M}=2,21, \mathrm{DP}=0,92 ; \mathrm{IC}_{95 \%}-2,04-2,38\right)[F(1,261)=3,66, p<0,05]$.

\section{DISCUSSAO}

De forma geral, independente da amostra, o modelo dos hábitos de lazer é adequado e consistente, assumindo como representação das atividades de hábitos de lazer em jovens e corroborando a evidência psicométrica e estrutural para amostra de jovens atletas e não atletas; desta maneira, considera-se, a partir dos resultados observados, que as atividades avaliadas por esse instrumento referem-se à disposição que o jovem tem ao repetir uma atitude com fins de distração ou entretenimento, quando já se cumpriu com todas as suas responsabilidades familiares ou escolares, disposições estas, influenciadas sejam por ordem de alguém - pais ou responsáveis - ou por sua própria iniciativa, representada por três fatores, de acordo com o que teoricamente se esperava, a saber:

- Hedonismo (refere-se aos hábitos que assumem uma característica de consumo, enfatizando prazer individual e imediato como único bem possível do indivíduo para 
Nilton S. Formiga, Gislane Melo, Verificação Empírica da Escala das Atividades de Hábitos de Lazer... Sérvulo Fernando C. Lima

que alcance, unicamente, seu próprio prazer), composto pelos hábitos navegar na internet, ir a shows, teatro, etc., encontrar-se com alguém (paquera, amigos, etc.), ir a bares, boates ou restaurantes, assistir programas de televisão, comprar roupas, jogar conversa fora, contar piadas, etc.

- Lúdico (diz respeito à utilização de jogos, passeios e divertimentos em geral, apresentando um caráter instrumental do hábito, isto é, trata-se de um agir da diversão, podendo ser experimentado sozinho ou em grupo, o qual também pode ser capaz de gerar uma socialização com outros quando vivido sozinho, por exemplo, ao jogar qualquer esporte ou passear de bicicleta o jovem poderá, nesse contexto, se relacionar com outras pessoas) composto pelos hábitos passear de bicicleta, patins, skate, etc., jogar vídeo game ou jogos de ação e aventura, praticar esportes (basquete, futebol, voleibol, etc), ir ao jardim zoológico, reservas ecológicas, etc.

- Instrutivo (enfatizando a experiência de aperfeiçoamento e crescimento desenvolvido pelos sujeitos e tornando-os capazes de escolhas de lazer diferenciadas e exclusivas para eles, assumindo uma atividade quanto a transmissão, habilitação e ensino de conhecimentos de forma que conduza a debates e discussões frente ao saber intelectual e de relação social e histórica familiar) formado pelos hábitos Ler livros, Ler jornais, Ler revistas, Visitar familiares (FORMIGA, BONATO \& SARRIERA, 2011, p.411-412).

Apesar de se observar que a estrutura fatorial da escala de hábitos de lazer se adequa para a amostra de jovens em diferentes contextos sociais, escolares e esportivos; os resultados da análise de variância revela que os jovens atletas têm como o foco no lazer hedonista prezando o prazer individual e imediato como único bem possível do indivíduo para que alcance, unicamente, seu próprio prazer; essa reflexão não pode ser 
Nilton S. Formiga, Gislane Melo, Verificação Empírica da Escala das Atividades de Hábitos de Lazer... Sérvulo Fernando C. Lima

vista como algo negativo, mas, que é função na dinâmica esportiva a busca do sucesso e êxito. Resultado esse que se aproxima a reflexão de Melo (2008), a qual atribui aos atletas a organização desse tipo de lazer capaz de influenciar a socialização de traços de personalidade que gere uma identidade cultural, familiar, social, etc., de conseguir vencer por si mesmo.

No que se refere a média das respostas dos não atletas ser superior no hábito de lazer instrutivos e lúdicos quando comparado a dos atletas, esta condição poderá ser refletida em relação a distribuição e organização do tempo a que cada um dos grupos destina aos estudos, êxito escolar e dinâmica familiar. Segundo Zenha, Resende e Gomes (2009) os fatores negativos de ser atleta se deve a menor dedicação e motivação para os estudos e aperfeiçoamento intelectual e cultural (por exemplo, a leitura, escrita, etc.). Um resultado nessa direção foi observado por Formiga e Dias (2002), para os quais, a investida em um hábito instrutivo está diretamente relacionado a dedicação e tempo de estudo e autoconceito de bom estudante. Sendo assim, tais resultados contribui não somente para se refletir sobre o tempo e organização do lazer entre os jovens e sua interferência nos estudos, mas, também, na distribuição e monitoramento dos responsáveis pela atividades de lazer nas escolas afim de que, não separe o atleta de seus estudos.

\section{CONSIDERAÇÕES FINAIS}

Espera-se que os objetivos deste estudo tenham sido atingidos, especialmente no que se refere à sua consistência da estrutura fatorial do instrumento das atividades dos hábitos de lazer em jovens atletas e não atletas; essa condição é importante porque sugere o emprego deste instrumento em áreas de estudo que cooperam com a psicologia, por exemplo: a educação, a sociologia, a educação física, etc. É também de grande valor 
Nilton S. Formiga, Gislane Melo, Verificação Empírica da Escala das Atividades de Hábitos de Lazer... Sérvulo Fernando C. Lima

o uso deste instrumento em espaços sociais, escolares ou de apoio à diversão e do ócio, visando à saúde psíquica e física (por exemplo, as colônias de férias, escolas de esportes, etc). A escala de hábitos de lazer mostrou-se fidedigna e acurada (nesta última, se considerarmos que, ao aplicar à amostra deste estudo, esta seria mais uma informação e apoio a consistência do instrumento em diferentes amostras), pois, mesmo com contexto amostral, a escala revelou indicadores úteis para a sua administração nos respectivos grupos de jovens.

Por fim, ao reavaliar a escala desenvolvida por Formiga, Ayroza e Dias (2005), a qual corroborada, em sua estrutura fatorial, por Formiga, Bonato e Sarriera (2011) com amostras brasileiras, mais uma vez, revelam-se resultados confiáveis com a amostra desse estudo. Assim, sugere-se acrescentar uma maior qualidade na mensuração dessa escala ao se avaliar o fenômeno do lazer em jovens em amostra tão distintas; a presente escala merece uma atenção tanto na aplicação em diferentes amostras quanto no avanço crítico para um futuro teste de avaliação psicológica da dinâmica do lazer ou do esporte nos jovens.

Os resultados aqui apresentados apontam para especificidade e indexação dos itens e seus respectivos fatores e que, a escala aqui avaliada, poderá ser considerada confiável quanto a mensuração, principalmente, quando se comparar a outros estudos que avaliaram a mesma escala em diferentes estados brasileiros (FORMIGA; BONATO; SARRIERA, 2011) e escolares (FORMIGA, 2012). Considerando os indicadores de bondade de ajuste, comprovou-se a estrutura e consistência interna da escala reforçando o seu emprego no contexto brasileiro para a avaliação das atividades dos hábitos de lazer e de variáveis antecedentes e consequentes desse construto (por exemplo, motivação e dedicação esportiva e acadêmica, vínculo afetivo, personalidade, 
Nilton S. Formiga, Gislane Melo, Verificação Empírica da Escala das Atividades de Hábitos de Lazer... Sérvulo Fernando C. Lima

etc.). Tais resultados garantem psicometricamente, através da equação de modelagem estrutural, que este instrumento é acurado na mensuração de construto.

\section{REFERÊNCIAS}

ANDRADE, J. V. Os consumidores do lazer. In: ANDRADE, J. V. (Org.). Lazer: Princípios, tipos e formas na vida e no trabalho. Belo Horizonte: Autêntica, 2001. p. 127-138.

ASSOCIAÇÃO NACIONAL DE PESQUISA E PÓS-GRADUAÇÃO EM PSICOLOGIA - ANPEPP. Contribuições para a discussão das Resoluções CNS nº. 196/96 e CFP N $\mathbf{N}^{\mathbf{0}}$ 016/2000. Disponível em: http://www.anpepp.org.br/XIISimposio/Rel_ComissaoEticasobre_Res_CNS_e_CFP.pdf . 2000 .

BILICH, F.; SILVA, R.; RAMOS. P. Análise de flexibilidade em economia da informação: modelagem de equações estruturais. Revista de Gestão da Tecnologia e Sistemas de Informação, v. 3, n. 2, p. 93-122, 2006.

BYRNE, B. M. A primer of LISREL: Basic applications and programming for confirmatory factor analytic models. New York: Springer-Verlag, 1989.

CONSELHO NACIONAL DE SAÚDE - CNS. Diretrizes e Normas Regulamentadoras de Pesquisas Envolvendo Seres Humanos. Disponível em: http://conselho.saude.gov.br/resolucoes/reso_96.htm. 1996.

DUMAZEDIER, J. Sociologia empírica do lazer. São Paulo: Perspectiva, 1999.

FORMIGA, N. S. Modelagem estrutural da escala de atividades de hábitos de lazer em jovens: Comprovação em diferentes contextos escolares no Brasil. Revista de Psicologia da UFC, v. 3, n. 1, 2012. No prelo.

FORMIGA, N. S.; AYROZA, I.; DIAS, L. Escala das atividades de hábitos de lazer: construção e validação em jovens. PSIC - Revista de Psicologia do Vetor Editora. v. 6, n.2, p. 71-79, 2005.

FORMIGA, N. S.; BONATO, T. N.; SARRIERA, J. C. Escala das atividades de hábitos de lazer em jovens: Modelagem de equação estrutural em diferentes contextos brasileiros. Temas em Psicologia, v. 19, p. 1-20, 2011.

FORMIGA, N. S.; DIAS, P. S. Correlatos entre hábitos de lazer e os indicadores do rendimento escolar. 2008. Disponível em : www.psicologia.com.pt. Acesso em: 07 de mar. 2002.

GARSON, G. D. PA 765 Statnotes: An online textbook. Disponível em: http://www2.chass.ncsu.edu/garson/pa765/statnote.htm . Acesso em: 29 out. 2009. 
Nilton S. Formiga, Gislane Melo, Verificação Empírica da Escala das Atividades de Hábitos de Lazer... Sérvulo Fernando C. Lima

HAIR, J. F.; et al. Análise Multivariada de Dados. Porto Alegre: Bookman, 2005.

KELLOWAY, E. K. Using LISREL for structural equation modeling: A researcher's guide. Thousand Oaks, CA: Sage Publications, 1998.

MARCELINO, N. C. Lazer e humanização. 3.ed. Campinas: Papirus, 2000.

MARCELINO, N. C. Lazer e sociedade: Múltiplas relações. Campinas: Alínea editora, 1998.

MELO, G. F. Perfil Psicológico de atletas brasileiros baseados na teoria do Individualismo-Coletivismo e na metodologia do modelo interativo. Brasília. 119f. Tese (Doutorado em Educação Física) - Universidade Católica de Brasília: Brasília, 2008.

PAIS, J. M. Gerações e valores na sociedade portuguesa contemporânea. Lisboa: ICS, 1998.

PERREIRA, J. V. Perspectivas do tempo livre para o lazer no Brasil. Boletim de Intercâmbio, v. 6, n. 32, p. 39-55, 1987.

REQUIXÁ, R. Características e funções do lazer. Boletim bibliográfico do SESC, v. 4, p. 31-34, 1974.

SAMPAIO, T. M. V.; SILVA, J. V. P. Lazer e cidadania: horizontes de uma construção coletiva. Brasília: Universa, 2011.

TABACHNICK, B. G.; FIDELL, L. S. Using multivariate statistics. Needham Heights, MA: Allyn \& Bacon, 1996.

VAN DE VIJVER, F.; LEUNG, K. Methods and data analysis for cross-cultural research. Thousand Oaks, CA: Sage Publications, 1997.

WERNECK, C. Questões contemporâneas. Significados e relações constituídas entre o lazer e a recreação no Brasil. In: WERNECK, C. Lazer, trabalho e educação: Relações históricas, questões contemporâneas. Belo Horizonte: UFMG. 2000. 80$126 \mathrm{p}$.

ZENHA, V.; RESENDE, R.; GOMES, A.R. Desporto de alto rendimento e sucesso escolar: Análise e estudo de factores influentes no seu êxito. In: CONGRESSO INTERNACIONAL DE DEPORTES DE EQUIPO EDITORIAL Y CENTRO DE FORMACIÓN ALTO RENDIMIENTO, 2., 2009., Corunha. Anais... Corunha, 2009. p. $1-10$. 
Nilton S. Formiga, Gislane Melo, Verificação Empírica da Escala das Atividades de Hábitos de Lazer... Sérvulo Fernando C. Lima

\begin{abstract}
ANEXO
Considere as frases abaixo e indique com que freqüência você ocupa seu horário de lazer, isto é, o tempo livre que tens quando você já cumpriu todas as atividades exigidas pela família, responsáveis ou escola. Para isso, circule ou marque com um $\mathbf{X}$ na escala de resposta ao lado de cada frase.
\end{abstract}

\title{
Hábitos Hedonistas
}

V1. Assistir programas de televisão.

Nunca $\begin{array}{lllllll}0 & 1 & 2 & 3 & 4 & 5\end{array}$

\section{Sempre}

V2. Ir a bares, boates ou restaurantes

$\begin{array}{lllllll}\text { Nunca } & 0 & 1 & 2 & 3 & 4 & 5\end{array}$

\section{Sempre}

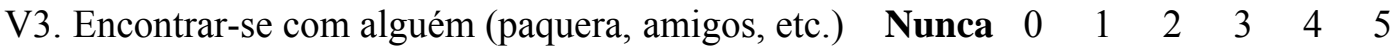

\section{Sempre}

V4. Jogar conversa fora, contar piadas, etc.

Nunca $\begin{array}{lllllll}0 & 1 & 2 & 3 & 4 & 5\end{array}$

Sempre

V5. Comprar roupas.

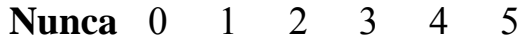

Sempre

V6. Navegar na internet (Orkut, MSN, etc.).

$\begin{array}{lllllll}\text { Nunca } & 0 & 1 & 2 & 3 & 4 & 5\end{array}$

Sempre

V7. Ir a Shows, teatro, etc.

$\begin{array}{lllllll}\text { Nunca } & 0 & 1 & 2 & 3 & 4 & 5\end{array}$

\section{Sempre}

\section{Hábitos Lúdicos}

V8. Passear de bicicleta, patins, skate, etc.

Nunca $\begin{array}{lllllll}0 & 1 & 2 & 3 & 4 & 5\end{array}$

\section{Sempre}

V9. Jogar vídeo game ou jogos de ação e aventura. $\quad \begin{array}{llllllll}\text { Nunca } & 0 & 1 & 2 & 3 & 4 & 5\end{array}$

\section{Sempre}

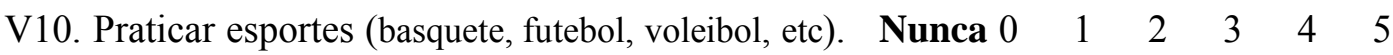
Sempre

V11. Ir ao jardim zoológico, reservas ecológicas, etc. $\quad \begin{array}{lllllll}\text { Nunca } & 0 & 1 & 2 & 3 & 4 & 5\end{array}$ Sempre 
Nilton S. Formiga, Gislane Melo, Verificação Empírica da Escala das Atividades de Hábitos de Lazer... Sérvulo Fernando C. Lima

\section{Hábitos Instrutivos}

V12. Ler livros

$\begin{array}{lllllll}\text { Nunca } & 0 & 1 & 2 & 3 & 4 & 5\end{array}$

Sempre

V13. Ler jornais.

$\begin{array}{lllllll}\text { Nunca } & 0 & 1 & 2 & 3 & 4 & 5\end{array}$

Sempre

V14. Ler revistas.

$\begin{array}{lllllll}\text { Nunca } & 0 & 1 & 2 & 3 & 4 & 5\end{array}$

Sempre

V15. Visitar familiares

$\begin{array}{lllllll}\text { Nunca } & 0 & 1 & 2 & 3 & 4 & 5\end{array}$

\section{Sempre}

\section{Endereço dos Autores:}

Nilton S. Formiga

Avenida Guarabira, 133 - Bairro de Manaíra

CEP.: 58038-140 - João Pessoa - PB

Endereço Eletrônico: nsformiga@yahoo.com 